\title{
The Development of Brand Association Measures in Multiple Product Categories: New Findings and Implications for Goods and Service Brands
}

\author{
Brian S. Gordon ${ }^{1}$, Jeffrey D. James ${ }^{2} \&$ Masayuki Yoshida $^{3}$ \\ ${ }^{1}$ Department of Health, Sport, \& Exercise Science, University of Kansas, Lawrence, USA \\ 2 Department of Sport Management, Florida State University, Florida, USA \\ ${ }^{3}$ Department of Sport Science, Biwako Seikei Sport College, Japan \\ Correspondence: Brian S. Gordon, Department of Health, Sport, \& Exercise Science, University of Kansas, \\ Room146C-1 Robinson Center, Lawrence, KS 66045-7567, USA. Tel: 785-864-4451. \\ Received: April 6, 2016 \\ doi:10.5430/ijba.v7n3p140 \\ Accepted: April 29, 2016 \\ Online Published: May 10, 2016 \\ URL: http://dx.doi.org/10.5430/ijba.v7n3p140
}

\begin{abstract}
Being able to determine the equity of a service or goods brand is of paramount importance to marketing practitioners and scholars alike. One way to determine the equity of a brand is through the measurement of brand associations. Few studies have constructed brand association measures in the context of either goods or service brands and most have been constructed to measure traditional goods brands. As Vargo and Lusch (2004) have indicated, the characteristics of a good differ greatly from those of a service. Therefore, the purpose of this study was to construct a separate brand association measure for the services and goods contexts. This study employed a mixed methods approach to generating and empirically testing brand association measures in both contexts. Thought-listing procedures with a sample of consumers $(n=72)$ were utilized to generate survey items for the service-based brand associations measure. To test the psychometric properties of the brand association measure, a sample of service consumers $(n=459)$ was utilized. Factor analysis procedures via MPlus 3.1 were utilized to examine the dimensionality of the service-based as well as the goods-based brand association measures. The result of this study was the construction of brand association measures that can be utilized in the goods or services contexts. It represents one of the first attempts to construct and compare brand association measures in both the goods and services contexts. Goods and services marketers can utilize these measures to determine how their consumers view their brand and they can track the success of their positioning efforts.
\end{abstract}

Keywords: brand associations, brand equity, service brand, goods brand, free thought association

\section{Introduction}

The importance of branding has been evident for traditional goods and service firms since the late 1980's (Srinivasan, Park, \& Chang, 2005). Research has consistently shown that there are numerous benefits of strong brands for both consumers and firms alike. For consumers, strong brands reduce the perceived risk and search costs, enhance the likelihood of future consumption, and can strengthen social identity by linking brand identity to their self-concept (Cobb-Walgren, Ruble, \& Donthu, 1995; Kayaman \& Arasli, 2007; Keller, 1993; Underwood, Baer, \& Bond, 2001). With a strong brand organizations can charge a premium price for their products, have the ability to gain market share, can maintain customer loyalty, offer successful brand extension opportunities and can influence consumers to spread positive word of mouth (Brady et al., 2008; Cobb-Walgren et al., 1995; Sangster, Wolton, \& McKenney, 2001).

Due to the importance of effective brand management for an organization, scholars have hypothesized and examined different sources of brand equity in order to determine how brand equity is established. Among these sources, brand associations have been a significant research area for numerous marketing scholars. Although brand association measures have been constructed utilizing multiple product categories as the basis for their construction, (see Aaker 1997; Bauer, Sauer, \& Exler, 2008; Checchinato, Disegna, \& Vescovi, 2013; Faircloth, Capella, \& Alford, 2001; Low \& Lamb, 2000; Romaniuk \& Gaillard, 2007; Uggla, 2004), scale items for measuring brand associations have 
not been validated separately in the goods and services contexts in the marketing literature. The current study addresses that limitation in the marketing literature.

A second limitation of previous research involves the contemporary conceptualization of brand associations which consists of brand attitudes and the overall brand image that are consumers' evaluative responses to brand associations themselves and should not be included in a measure of brand associations. Brand associations are considered any thoughts linked to the brand in the mind of the consumer (Aaker, 1991). Therefore, the purpose of this study was to construct separate brand association measures for good and service product categories. The specific direction of this research was guided by the strengths and weaknesses of previous work. The following section examines conceptual background of brand associations and the strengths and weaknesses of previous measures.

\section{Literature Review}

\subsection{Defining Brand Association}

Keller (1993) labeled brand image as "a set of associations linked to the brand that consumers hold in memory" (p.3). A brand image is composed of a set of associations regarding the brand in the mind of the consumer. Brand associations are the informational nodes that contain the meaning of the brand in the mind of the consumer (Keller, 1998). Brand associations are considered to be any thought linked to a brand in the mind of the consumer (Aaker, 1991; 1996). Marketers use brand associations for product positioning purposes while consumers use brand associations to help guide their decision-making (Low \& Lamb, 2000). Scholars have held differing opinions on what constitutes a brand association as well as how these associations should be categorized.

Brand associations were classified into three categories by Keller (1993): attributes, benefits, and attitudes. Attributes, descriptive features that characterize a product or service, are divided into product and non-product related categories. Product-related attributes are the ingredients necessary for the performance of the good or service sought by the consumer. Non-product attributes are the external aspects of a product such as price, packaging, and usage imagery.

Benefits are the personal value consumers attach to the product or service attributes and are categorized into three types of benefits: functional, experiential, and symbolic. Functional benefits are intrinsic advantages of the product related to product attributes. These benefits are often associated with basic motivations, such as safety and physiological needs (Maslow, 1970). Experiential benefits are the feelings associated with the use of the product. These benefits relate to pleasure seeking and are closely associated with hedonic values. Symbolic benefits refer to extrinsic benefits such as social status or prestige tied to the good or service. These benefits correlate with non-product benefits and include social status, prestige, and an enhancement of self-esteem and self-concept.

Keller defines attitudes as the consumers' overall evaluations of the brand and these often form the basis for consumption behavior. Attitudes are often characterized by their favorability, strength, and uniqueness. Favorability refers to how the product satisfies the consumers' needs or wants. The level of strength is determined by the extent to which brand image enters and is maintained in the mind of the consumer. Uniqueness simply is how much that information recall relates to the particular brand in question.

The theoretical foundation of brand associations as set forth by Keller (1993) aided marketing researchers in determining the importance of brand associations from a consumer behavior standpoint. The following section details research that has examined the importance of brand associations from a marketing perspective.

\subsection{Why Study Brand Associations?}

The importance of brand associations is evident when examining the literature on brand equity. Brand equity is the value added to a product by a particular mark, name, or symbol (Aaker, 1991). It has been posited that strong brand equity is related to outcomes such as an increase in customer loyalty, willingness to accept brand extensions, and willingness to pay a premium price for the target brand (Keller, 1993). Keller (1993) proposed that brand knowledge (brand equity) was comprised of two dimensions: brand awareness and brand associations. Due to the fact that building brand equity can have such positive results for an organization, it stands to reason that creating favorable associations on behalf of consumers is a primary objective of brand managers.

The impact of brand associations on building brand equity has been strongly suggested by researchers. Keller (1993) believed that brand associations represent the most important component of brand equity. Berry (2000) conceptualized service brands in his model of brand equity and concluded that the meaning of the brand in the mind of the consumer (overall brand image) had a direct impact on the level of brand equity for a service brand. He posited that the brand meaning, a compilation of brand associations that lead to the overall meaning of the brand for the consumer, disproportionately affects brand equity in comparison to brand awareness. The perception of the brand 
is more critical to brand equity then the mere presence of the brand in the mind of the consumer. Strong brand associations combine to form the overall image or meaning of the brand for the consumer (Yoo, Donthu, \& Lee, 2000). Further, the personality of a brand can have a significant impact on the consumer's final decision to purchase the brand (Kim, Lee, \& Lee, 2008).

Del Rio, Vazquez, and Iglesias (2001) found that positive brand image was correlated with consumer's willingness to pay a price premium, recommend the brand to friends, and the willingness to accept brand extensions. These consequences have been supported in the literature as outcomes of brand equity and have served as proxy measures of brand equity. By utilizing the benefits aspect of brand associations, the authors constructed four types of brand functions from the perception of the consumer: guarantee, personal identification, social identification, and status. It was believed that these brand functions were representative of the utility and benefits that brands offered to consumers. In addition to the aforementioned benefits of crafting a positive brand image, a positive image positively influences brand loyalty (Moon, Park, \& Choi, 2010).

As marketers and researchers alike of come to understand the potential benefits of brand associations, scholars have engaged in scale construction to develop brand association measures for multiple product contexts. The following section details these attempts at measurement as well as the limitations of each.

\subsection{Brand Association Measurement}

Although Low and Lamb (2000) found support for their multi-dimensional conceptualizations of brand associations, their results are in direct conflict with the conceptualization of brand associations put forth by Keller. Brand associations are merely thoughts linked to the brand in the mind of the consumer (Keller, 1993) and as a result, the associations do not carry an evaluative or emotional component to them. Therefore, the inclusion of brand attitude and brand image as conceptualized in the proposed studies stands in stark contrast to the manner in which brand associations have been defined. Although Keller conceptualizes brand attitudes as a type of brand association, it will be argued here that brand attitudes constitute a consumer's cognitive response to the associations they hold for a given brand.

A consumer's emotional and rational responses to a brand as well as the overall judgment are not specific aspects of brand associations. Rather, brand attitude and overall brand image are responses to specific brand associations in the mind of the consumer. Therefore, brand attitude and overall brand image should be positioned as responses that occur following the formation of brand associations. A more valid conceptualization of brand associations was put forth by Faircloth, et al. (2001). They examined the impact of brand associations on consumers' attitudes and overall image. They found that specific brand associations can have a positive impact on the overall brand image that, in turn, influence brand attitudes. This finding contradicts Keller's (1993) assertion that brand attitudes represent a specific type of brand association. Instead, this study shows that brand associations are separate from brand attitudes and that these associations aid in the formation of attitudes toward the brand by consumers.

The preceding literature illustrates the conceptual confusion regarding the dimension of brand attitude. Due to the evaluative nature of attitudes, this dimension should not be included as a specific type of association. More likely, brand attitudes are closely related to an attitudinal outcome of brand associations or a moderator between brand associations and consumer outcomes such as attitudinal loyalty or behavioral intentions. In fact, Bauer et al. (2008) found that brand attitudes shared the strongest relationship with brand loyalty and brand attitudes were closely related to the attitudinal aspect of loyalty. Therefore, brand attitudes should be viewed as a response that is formed due to the brand associations that exist in the mind of the consumer. Therefore, in the context of this study, brand associations will be defined as the mere thoughts that consumers hold for a given brand and can be characterized by two dimensions: attributes and benefits.

With this study, the researchers attempt to construct brand association measures that can be utilized in multiple goods and services contexts. This will be achieved by directly eliciting brand association from consumers in multiple goods and services contexts. Few previous studies have utilized a free thought-listing procedure to generate the items for a brand association measure (see Nelson, McEvoy, \& Dennis, 2000; Supphellen, 2000; Till, Baack, \& Waterman, 2011). Keller (1993) and Supphellen (2000) have argued that brand associations reside in the mind of the consumer thus a direct elicitation of associations from the consumer would provide the most accurate measure. Furthermore, Supphellen posited that the only valid manner to establish brand associations is through a qualitative inquiry directly from consumers. Therefore, this study will directly elicit brand associations from consumers as a foundation to build separate measures for the goods and services context. The following section details the procedures utilized to construct the brand association measure for the goods and services. 
This study mirrored the scale development procedures put forth by Gwinner, Gremler, and Bitner (1998) in their examination of relational exchange in the service context. Two studies were completed in order to construct separate brand association measures for goods and services that are believed to be necessary for brand managers that manage both tangible and intangible products. First, a qualitative study (Study 1) was completed from which the items for the brand association measure were developed. Study 1 was a direct elicitation of brand associations from consumers in order to generate specific items for the measures. Study 2 tested the brand association items via a survey questionnaire and examined the relationship among the items and their psychometric properties by means of factor analysis.

\section{Study 1}

\subsection{Method}

Brand associations were generated from two goods contexts (athletic footwear \& automobiles) and two service contexts (amusement parks \& restaurants). Besides the goods and services distinction, there were additional criteria that influenced our product choices. The goods context is comprised of a low involvement (athletic footwear) versus high involvement (automobile) product as well as two products that may be consumed for both hedonic and utililitarian reasons. In regards to the services context, the amusement park context was chosen as a highly experiential service context where consumers may be driven by hedonic motives to consumer the product. In contrast, the restaurant context may contain elements of hedonic consumption motives but more than likely, the decision to consume is a utililitarian one.

A separate brand association measure for each product setting was established. This was necessary due to the diverse nature of brand associations. Brand associations were elicited directly from consumers by means of a thought-listing procedure. The thought-listing form was constructed to assess the associations respondents held for one of four different products. For the goods context, associations were identified for automobiles and athletic footwear. The services context was comprised of amusement parks and restaurants. Respondents were asked to think of their favorite brand in the respective product category and list the first thoughts that came to mind.

\subsection{Sample}

Seventy-two thought-listing forms for the goods context were administered to undergraduate students in sport management courses at a large southeastern university. Sixty-nine forms were deemed usable for analysis for a response rate of $95.8 \%$. Of these sixty-nine forms, thirty-four respondents completed a thought-listing form in the context of their favorite athletic footwear brand while thirty-five respondents completed a thought-listing form in the context of their favorite automobile brand. Seventy-five thought listing forms for the services context were administered to a different group of undergraduate students at the same university. Seventy-one forms were utilized for analysis which constitutes a response rate of $94.6 \%$. Of these seventy-one forms, thirty-four respondents completed a thought-listing form in context of their favorite restaurant brand while thirty-seven respondents completed a thought-listing form in the context of their favorite amusement park.

Thought-listing forms were discarded when respondents failed to complete the form or when they did not follow the directions specified. For example, two respondents did not provide thoughts related to the brand on the form and as a result, their forms were discarded from analysis. When determining the adequate sample size, 20-30 observations are needed to adequately capture approximately $95 \%$ of responses by consumers (Griffin \& Hauser, 1992). Accordingly, the number of completed thought listing forms for each product category was deemed adequate.

\subsubsection{Goods}

A total of 34 athletic footwear brand thought-listing forms were completed. Respondents were comprised of 25 (73.5\%) males and nine (26.4\%) females. The average age was 20.9 years; the sample included $19(55.8 \%)$ juniors and $15(44.2 \%)$ seniors. The racial makeup was 28 (82.3\%) Caucasian, three (8.8\%) African-American, two (5.8\%) Latino, and one (2.9\%) Asian.

A total of 35 automobile brand thought-listing forms were completed. Respondents were comprised of 26 (74.3\%) males and nine $(25.7 \%)$ females. The average age 20.6 years; the sample included three $(8.6 \%)$ sophomores, 17 (48.6\%) juniors, and $15(42.9 \%)$ seniors. The racial makeup was 24 (68.6\%) Caucasian, nine (25.7\%) Latino and two (5.7\%) Asian.

\subsubsection{Services}

A total of 34 restaurant brand thought-listing forms were completed. Respondents were comprised of $22(64.7 \%)$ males and $12(35.3 \%)$ females. The average age was 21.2 years; the sample included $24(70.6 \%)$ juniors and 10 
(29.4\%) seniors. The racial makeup was 28 (82.4\%) Caucasian, four (11.8\%) African-American, one (2.9\%) Latino and one (2.9\%) Asian.

A total of 37 amusement park thought-listing forms were completed. Respondents were comprised of 27 (73\%) males and $10(27 \%)$ females. The average age was 20.7 years; the sample included one (2.7\%) freshman, six (16.2\%) sophomores, 13 (35.1\%) juniors, and 17 (46\%) seniors. The racial makeup was 33 (89.2\%) Caucasian, two (5.4\%) African-American, and two (5.4\%) Latino.

\subsection{Data Analysis}

The purpose of the thought-listing procedure was to determine the most salient thoughts that consumers held for their favorite brand in two goods (automobile \& athletic footwear) and two service (amusement park \& restaurant) categories. A content analysis procedure was employed involving two coders and one of the researchers. The two coders were doctoral students in a graduate program at a large southeastern university. The three coders analyzed the data independently. The coders were instructed to categorize the brand associations for each good and service and provide broad labels and operational definitions for every category identified.

\subsection{Results of Study 1}

\subsection{Goods}

In order to determine the total number of thoughts for each product category, all thoughts were counted in the descriptive analysis. The 69 respondents listed a total of 107 thoughts regarding their favorite brand of athletic shoe. For the automobile brand context, 110 thoughts were listed; duplicate thoughts were included in the count.

For the athletic footwear category, the three coders agreed upon 7 out of 8 categories for an agreement level of $87.5 \%$. For the automobile category, two out of the three coders identified eight categories while the third coder only identified seven categories. Those seven categories were in agreement with the results of the other two coders; the eighth category for the two coders was different. The three coders agreed upon 7 out of 9 categories for an agreement level of $78 \%$. When there was disagreement among coders, those differences were reconciled through discussion between the three coders.

Since the overall objective was to build a brand association measure based on the elicitation of associations from two different goods, the results of the independent codings and subsequent thoughts were merged to develop a final list of items for the goods context. There were 16 items that could be generalized across the automobile and athletic footwear contexts (see Table 1). Those items were utilized in the survey questionnaire in Study 2. It is important to note that a significant number of thoughts were discarded due to the lack of agreement across both the athletic footwear and automobile contexts. A majority of the brand associations simply were not commonly held across both product categories. Also, a majority of the thoughts held for athletic footwear or automobiles were consistently repeated by multiple respondents which tended to inflate the overall number of thoughts held for each brand. Therefore, the 16 items that were utilized for further analysis represent the common thoughts that consumers held for automobiles and athletic shoes.

\subsection{Services}

The 71 respondents listed 156 thoughts regarding their favorite brand of amusement park. In regards to their favorite restaurant, the respondents listed a total of 146 thoughts; duplicate thoughts were included in the analysis. For the content analysis procedure, duplicate thoughts were included because it is vital to determine which thoughts were most frequently occurring in the context of each brand category. The coders were instructed to identify the most commonly listed thoughts for each product category level (i.e. amusement park and restaurant). The coders next organized the thoughts into broad categories for the content analysis procedure. This was done in an effort to compute the reliability coefficient as well as compare the brand associations in their respective service contexts. The common categories and thoughts could be merged to form the basis for a brand association measure in the service context.

For the amusement park context, two of the three coders identified and agreed upon eight categories while the third coder identified nine categories, eight of which were agreed upon by all three coders. The intercoder reliability for the amusement park category was $89 \%$. For the restaurant category, two of the coders identified seven categories and one coder identified six categories, which all three coders agreed upon. Seven total categories identified, six of which were agreed upon by all three coders for an $85.7 \%$ level of agreement.

Since the objective was to establish a general measure of service brand association based on the thoughts elicited from the two service contexts, the subsequent items were compared across the two services and similar items were 
utilized in the survey questionnaire for Study 2. A total of 23 items were identified and deemed usable for Study 2 (see Table 1). It is important to note that a significant number of thoughts were discarded due to the lack of agreement across both the amusement park and restaurant contexts. A majority of the brand associations were not commonly held across both service brands. Also, similar to the goods context, a majority of the thoughts held for amusement parks or restaurants were consistently repeated by multiple respondents which increased the overall number of thoughts held for each brand. Therefore, the 23 items that will be utilized for further analysis represent the common thoughts that consumers held across both services contexts.

Table 1. Brand association items for goods and services context

\begin{tabular}{ll}
\hline & Brand Association Items from Study 1 \\
\hline \multicolumn{1}{c}{ Goods } & \multicolumn{1}{c}{ Services } \\
Performance & Fun atmosphere \\
Comfort & Excitement \\
Durability & Friends \\
Enjoyment & Fun \\
Quality & Family \\
Brand name & Enjoyment \\
Brand logo & Entertainment \\
Specific name of product & Cheap \\
Brand color & Affordable \\
Affordable & Quality \\
Cheap & Helpful employees \\
Expensive & Friendly employees \\
Design & Knowledgeable employees \\
Fun & Brand name \\
Good feelings & Brand color \\
Style & Specific name of product \\
& Brand logo \\
& Specific product offering \\
& Relaxation \\
& Socializing \\
& Friendly atmosphere \\
& Relaxing atmosphere \\
\hline
\end{tabular}

\section{Study 2}

\subsection{Method}

The next step was to test the brand association items in order to uncover their latent factor structure and to assess their psychometric properties. In Study 1, 23 items for service brand associations and 16 items for goods brand associations were identified. Since the objective was to create a separate brand association measure for goods and services, a separate questionnaire was used for each product category and two separate data collections were conducted. For this study, a sport product was selected as a focal brand category for the goods and services context. The respondents were asked to select their favorite professional sports team brand for the services context or their favorite brand of athletic footwear in the goods context.

Data were subjected to exploratory factor analysis by SPSS 15.0. The exploratory factor analysis utilized principal axis factoring with oblique rotation. Exploratory factor analysis was deemed appropriate due to the fact that there was a lack of previous empirical evidence to suggest how many factors would emerge based on the categories generated from the thought-listing task in Study 1. A determination of factor retention centers on keeping the factors that account for the most variance. Therefore, a number of criteria were utilized to decide how many factors to retain.

First, the Kaiser criterion was employed whereas factors that have an eigenvalue greater than one are considered common factors (Nunnally, 1978). Catell's (1966) scree test was a second method utilized to determine factor retention. Finally, a number of identifiability criteria were employed. These criteria included the number of 
significant loadings (>.50) on a given factor, common loading variables sharing similar conceptual meaning, different loading variables having distinct conceptual meaning, and the degree to which the rotated factor structure illustrates a simple structure (Suhr, 2006).

\subsection{Sample}

A convenience sample of 500 undergraduate students in physical education courses at a large southeastern university completed either a goods or services questionnaire. The reasoning for selecting a student sample was two-fold. Students are an easily identifiable and accessible segment of the population. Also, college students are significant consumers of spectator sports and sporting goods. Of the 250 surveys administered in the services context, 231 were deemed usable for analysis for a response rate of $92.4 \%$. In the goods context, 228 survey questionnaires were deemed usable for analysis for a response rate of $91.2 \%$. In both contexts, uncompleted surveys and surveys with a lack of variability in responses were discarded from analysis.

The sample of respondents $(\mathrm{n}=231)$ for the services survey questionnaire included $161(69.6 \%)$ males and $70(30.3 \%)$ females. The average age of the respondents was 21.1 years. In terms of race, there were 184 (79.6\%) Caucasians, 33 (14.2\%) African-Americans, seven (3\%) Latino, and seven (3\%) Asian. For the goods context $(\mathrm{N}=228)$, there were $148(64.9 \%)$ males and $80(35 \%)$ females. The average age of the respondents was 20.8 years age. There were 193 (84.6\%) Caucasians, 25 (10.9\%), 7 (3\%) Latino, and 3 (1.3\%) Asian.

\subsection{Results of Study 2}

\subsection{Goods}

An examination of the eigenvalues for the initial exploratory factor analysis (see Table 2) indicated that four factors had eigenvalues greater than one (Hair et al., 2006). Cumulatively, the four factors accounted for $65.85 \%$ of the total variance. The scree test revealed there were two points on the scree plot that can be characterized as "elbows". The first elbow point appears after the extraction of the second factor while the second elbow point exists after the point on the fourth factor. Catell's (1966) guidelines call for the retention of factors before the elbow joint and to discard the factors beyond the "elbow" point. In this case, the scree test was inconclusive due to the existence of two "elbow" points.

Table 2. Variance explained by exploratory factor analysis in a goods context

\begin{tabular}{llll}
\hline & & $\begin{array}{l}\text { Extracted Sums of } \\
\text { Squared Loadings }\end{array}$ & $\begin{array}{l}\text { Rotated Sums of } \\
\text { Squared loadings }\end{array}$ \\
\hline Factor & Eigenvalue & Cumulative \% & Total \\
1 & 5.579 & 34.866 & 4.707 \\
2 & 2.135 & 48.211 & 3.859 \\
3 & 1.612 & 58.283 & 2.298 \\
4 & 1.051 & 65.852 & 1.241 \\
\hline
\end{tabular}

The Kaiser criterion indicated that four factors should be retained after accounting for the factor rotation while the scree test indicated that two or four factors should be retained. Since the results were mixed, it was necessary to consider further criteria for factor retention. First, an examination of the number of significant factor loadings for each extracted factor was conducted. For a factor loading to be considered significant, it needs to have a value greater than .50 (Hair et al., 2006). An examination of the pattern matrix, as seen in Table 3, revealed there were five items with factor loadings greater than .50 for factor 1. Factor 2 had four items with factor loadings above the .50 cutoff. Factor 3 had two items with factor loadings greater than .50, while factor 4 only had one item with a factor loading which exceeded the .50 cutoff. Factor 3 contained two items with factor loadings greater than .50 as well as a common conceptual meaning. In regards to factor 4, although only one factor loading was larger than .50 , this factor was also retained due to the conceptual commonality among the items because the common conceptual meaning regarding the items was an important determinant in retaining the factor. 
Table 3. Pattern matrix of rotated factor solution in a goods context

\begin{tabular}{|c|c|c|c|c|c|}
\hline Items & Factor 1 & Factor 2 & Factor 3 & Factor 4 & Communality \\
\hline Performance & .808 & & & & .646 \\
\hline Comfort & .873 & & & & .718 \\
\hline Durability & .766 & & & & .672 \\
\hline Enjoyment & .552 & & & & .627 \\
\hline Quality & .792 & & & & .613 \\
\hline Brand name & & .723 & & & .637 \\
\hline Brand logo & & .818 & & & .695 \\
\hline $\begin{array}{l}\text { Name of } \\
\text { product }\end{array}$ & & .818 & & & .672 \\
\hline Brand color & & .485 & & & .500 \\
\hline Affordable & & & .842 & & .805 \\
\hline Cheap & & & .921 & & .838 \\
\hline Expensive & & & & .569 & .513 \\
\hline Design & & & & .469 & .591 \\
\hline Fun & & & & .436 & .636 \\
\hline Good feelings & & & & & .562 \\
\hline Style & & & & & .653 \\
\hline
\end{tabular}

An examination of the conceptual meaning of each latent factor was employed as another criterion in factor retention. This means that each retained factor should retain items that share a similar conceptual meaning. The five items that represent factor 1 were performance from product use, comfort, durability, enjoyment from product use, and quality. Conceptually, these items all represent benefits from the use of particular good. Benefits are defined as the personal value consumers attach to the product or service attributes (Keller, 1993). Durability and quality can be viewed as functional benefits of the product. Performance from product use, comfort, and enjoyment can be characterized as experiential benefits. Factor 2 included four items: brand logo, name of specific product, brand name, and color. These items all relate to specific attributes of a particular good. Attributes are defined as descriptive features that characterize a product or service (Keller, 1993). Brand logo, brand color, brand name, and name of specific product are non-product related attributes related to packaging and imagery. This indicates that the goods brand association measure is represented by two factors: benefits and attributes. As alluded to above, factor 3 contained two items with common conceptual meaning regarding price. Price has long been considered a brand association that can be characterized as a non-product related attribute (Keller, 1993). Specifically, these items represent competitive pricing or a discount for the focal goods brand. In regards to factor 4, Design and fun are important elements for capturing the intangible image and feeling related to the brand while expensive relates to the intangible positive image attributable to the brand.

A final criterion utilized was an examination of the rotated factor matrix for signs of a simple structure. A simple structure exists when items have high loadings on one particular factor and low loadings on all other factors. This can be achieved by examining the factor loadings in the pattern matrix. Table 3 illustrates the factor loadings. An analysis of the pattern matrix revealed that all the items for factor 1 had high loadings while having low loadings on all other factors. The items for factor 2 had high loadings while having low loadings on all other factors. Factors 3 and 4 also do not display evidence of item cross-loading. This provided evidence that the retained four factors had a simple structure. Collectively, four factors emerged and were interpreted as benefits, attributes, discount, and imagery.

\subsection{Services}

The results of the initial exploratory factor analysis indicated that five factors emerged with eigenvalues greater than 1 and should be retained as illustrated in Table 4 . The total amount of variance explained by the five factors was $63.82 \%$. The scree test did reveal a clear "elbow" point on the graphic. The test indicates there are five meaningful factors extracted from the data. 
Table 4. Variance explained for each factor by exploratory factor analysis in a services context

\begin{tabular}{llll}
\hline & & $\begin{array}{l}\text { Extracted Sums of } \\
\text { Squared Loadings }\end{array}$ & $\begin{array}{l}\text { Rotated Sums of } \\
\text { Squared loadings }\end{array}$ \\
\hline Factor & Eigenvalue & Cumulative \% & Total \\
1 & 8.167 & 35.508 & 6.846 \\
2 & 2.364 & 45.786 & 2.249 \\
3 & 1.709 & 53.217 & 3.791 \\
4 & 1.352 & 59.097 & 3.212 \\
5 & 1.087 & 63.823 & 3.148 \\
\hline
\end{tabular}

The Kaiser criterion and scree test indicated that five factors should be retained after accounting for the factor rotation. Although the initial tests were in agreement, further criteria were evaluated for factor retention. First, an examination of the number of significant factor loadings for each extracted factor was conducted. An examination of the pattern matrix as seen in Table 5 revealed there were seven items with factor loadings greater than .50 for factor 1. Factor 2 had three items with factor loadings above the .50 cutoff and factor 3 had four items with loadings greater than .50. Factor 4 and factor 5 each had three items with factor loadings of $>.50$. An examination of the conceptual meaning of each factor was necessary to ensure that each item representing the latent factor shared significant conceptual meaning. The six items that represent factor 1 were fun, fun atmosphere, excitement, spending time with friends, spending time with family, and enjoyment. Entertainment was dropped from factor 1 due to its cross loading with factor 3. Conceptually, these items all represent benefits from the use of particular service.

Table 5. Pattern matrix of rotated factor solution in a service context

\begin{tabular}{|c|c|c|c|c|c|c|}
\hline Item & Factor 1 & Factor 2 & Factor 3 & Factor 4 & Factor 5 & Communality \\
\hline Fun atmosphere & .776 & & & & & .695 \\
\hline Excitement & .854 & & & & & .770 \\
\hline Friends & .782 & & & & & .657 \\
\hline Fun & .901 & & & & & .779 \\
\hline Family & .680 & & & & & .557 \\
\hline Enjoyment & .773 & & & & & .657 \\
\hline Entertainment & .523 & & -.550 & & & .687 \\
\hline Cheap & & .737 & & & & .625 \\
\hline Affordable & & .747 & & & & .664 \\
\hline Quality & & .519 & & & & .424 \\
\hline Helpful employees & & & -.742 & & & .734 \\
\hline Friendly employees & & & -.784 & & & .786 \\
\hline $\begin{array}{l}\text { Knowledgeable } \\
\text { employees }\end{array}$ & & & -.634 & & & .591 \\
\hline Brand name & & & & .794 & & .674 \\
\hline Brand color & & & & .495 & & .556 \\
\hline Name of product & & & & .389 & & .498 \\
\hline Brand logo & & & & .675 & & .728 \\
\hline Specific offering & & & & .416 & & .518 \\
\hline Relaxation & & & & & -.762 & .685 \\
\hline Socializing & .379 & & & & -.570 & .639 \\
\hline Friendly atmosphere & .410 & & & & -.512 & .597 \\
\hline Relaxing atmosphere & .376 & & & & -.476 & .595 \\
\hline Expensive & & & & & & .395 \\
\hline
\end{tabular}

An examination of factor 2 revealed that two items related to the price of a service brand and one item dealt with quality. For many service firms and retailers, the utilization of price as a heuristic cue is a keystone element of their brand image and a method to establish a competitive advantage over their competitors. Therefore, factor 2 was retained and relates to the concept of "discount" as a brand association. Factor 3 included four items: friendly employees, helpful employees and knowledgeable employees, and entertainment. Aside from entertainment, these 
items represent the characteristics of service employees, a key aspect of the service experience. This factor was retained with the exclusion of the item related to entertainment.

Factor 4 contained five items which were brand name, brand logo, brand color, name of product, and specific product offering. Since the two items pertaining to a specific product did not have sufficient factor loadings, they were dropped from this dimension. Although the brand color item did not reach the cutoff point, its exclusion would fundamentally limit the conceptual meaning of the factor thus it was kept as the third item in factor 4. Collectively, these three items represent the specific attributes of a given brand mark. Specifically, these items can be characterized as non-product attributes. Although factor 5 had three items with large factor loadings, most of the items cross-loaded with factor 1 . This stands to reason since the items in both factors deal with the specific benefits of service brand consumption. Recognizing the limitations with factor 5, we decided to retain this factor for further analysis. Since two of the items dealt with social interaction, the factor was entitled social benefits.

Based on the results of the exploratory factor analysis for the services context, five factors were retained. The items in factor 1 clearly capture the benefits of consuming a service product. For the most part, these benefits can be described as experiential benefits of service product consumption. The items in factor 3 describe specific characteristics of service employees, an integral part of the service experience. Factor 4 contains items that deal with the imagery of a service brand such as the logo, name, and colors. These items can be considered non-product attributes. Collectively, the services context contained three retainable factors: benefits, service, and attributes. The factor names and respective items for the goods and services context can be viewed in Table 6 .

Table 6. Goods and services factor names and items

\begin{tabular}{ll}
\hline & Factor Names \\
\hline Benefits & Goods \\
Performance & Benefits \\
Comfort & Fun atmosphere \\
Durability & Excitement \\
Enjoyment & Friends \\
Quality & Fun \\
& Family \\
Attributes & Enjoyment \\
Brand name & \\
Brand logo & Discount \\
Brand color & Cheap \\
Name of a specific product & Affordable \\
& Quality \\
Discount & \\
Affordable & Service \\
Cheap & Helpful employees \\
& Friendly employees \\
Imagery & Knowledgeable employees \\
Expensive & \\
Design & Attributes \\
Fun & Brand name \\
& Brand color \\
& Brand logo \\
& \\
& Social Benefits \\
& Relaxation \\
& Socializing \\
& Friendly atmosphere \\
\hline
\end{tabular}

\section{Conclusion and Implications}

It is clear from the results of this study that consumers hold a bevy of associations toward brands in both the goods 
and services categories. It is imperative for managers to understand what their consumers think about their brand and this measurement scale for both product categories is an initial step in that direction. Specifically, it is important to contrast the brand associations consumers hold between goods and services. For both contexts, the results of the exploratory factor analysis illustrated most consumers hold brand associations related to the attributes and benefits of a product. The benefits in the goods context were very tangible and functional attributes such as quality, comfort, and performance. By contrast, most consumers thought of visceral or experiential benefits in the services context such as excitement, enjoyment, and fun. This stands to reason when we consider one of the key differences between goods and services which is the intangible, experiential experience of consuming a service (Berry, 2000). Furthermore, most respondents indicated that characteristics of the service employee were also significant associations they held toward service brands. This result illustrates the importance of the interaction between service employees and consumers.

This study provides a solid foundation for managers of goods and services brands. Managers can utilize these results when crafting marketing and communication messages regarding their product. For example, a new line of athletic footwear should focus on communicating the functional attributes of the product such as quality, comfort, and performance. It is also important to construct a meaningful brand name, colors, and logo due to the fact that these associations were front and center in the mind of the consumers. In the services context, brand managers need to focus their marketing communications on the experiential benefits of their product such as fun, excitement, and enjoyment. In the service environment, it is important to create an experience that appeals to the senses and leaves a lasting impression on consumers. Similar to the goods context, attention needs to be paid to the construction and communication of the brand imagery. Finally, service managers need to be cognizant of the training and implementation of front-line service employees. Respondents in this study consistently thought of the friendliness and knowledge level of among this group of employees. Due to the subjective, inconsistent nature of service exchanges, it is paramount that service employees are personable, adequately trained, and provide an exemplary level of customer service. Achieving these objectives will influence the strength and favorability of brand associations that consumers hold toward the service brand.

From a measurement standpoint, this research endeavor illustrated the homogeneity of brands from the consumer perspective. One of the glaring limitations of this study was the lack of associations that could be generalized across service or goods brands. Since this study elicited associations from two different goods and services brands and merged the results of this elicitation, it was clear that only a few associations were evident in both settings. Since consumers' thoughts are so diverse depending on the brand, it is clear that a general service or goods brand association measure is not attainable. Instead, the focus of future research should be to construct a measure of brand associations that can be generalized across a specific product category. For example, in the athletic footwear category, a brand association measure can be constructed by eliciting consumers' thoughts for numerous brands (e.g., Nike, Adidas, Puma, and Asics) within this product category. Therefore, future research should continue to assess brand associations in both the goods and services contexts.

A related point on this subject is the argument between constructing a parsimonious measurement model and a model that captures the wide array of brand associations that consumers hold for a specific brand. One of the criticisms levied against the other brand association scales is that they contain too many items for practical application. The brand association measure in this study is very parsimonious for the goods and services context yet it clearly does not capture the full range of thoughts that consumers hold for a brand. Since brands are so diverse, thus creating a multitude of associations in the mind of the consumer, brand association research suffers from a "black hole" phenomenon. Therefore, future research needs to balance this apparent contradiction between creating a measure with construct validity and parsimony. Researchers should focus on constructing measures that can only be generalized to the product category level. Likewise, in the context of this study, there were a number of unique brand associations that did not generalize across product categories (i.e. athletic footwear and automobiles). Therefore, the results in this study suggest that a general goods or service brand association measure is not an attainable goal due to the lack of brand parity across product categories. Instead, the thoughts generated from Study 1 could form the basis for a measure in each of the four contexts studied (automobile, athletic footwear, restaurants, amusement parks). Further consumer elicitation can compliment the results of this study to form a measure with greater construct validity.

The current study was driven by important research questions including what brand associations exist in each of goods and service contexts and how factor structures differ across the two settings. The results indicated that brand associations in a goods context consisted of four dimensions, whereas five dimensions emerged in a service setting. The current study represents an initial effort to provide brand managers with more holistic information pertaining to 
the specific components of brand associations based both on tangible goods and intangible services. The results merit further marketing research with respect to formulating an explanation of what factors contribute most to driving brand equity through tangible and intangible products.

\section{References}

Aaker, D. A. (1991). Managing brand equity: Capitalizing on the value of a brand name. New York: Free Press.

Aaker, D. A. (1996). Building strong brands. New York: McMilian.

Aaker, J. L. (1997). Dimensions of brand personality. Journal of Marketing Research, 34(3), 347-356. http://dx.doi.org/10.2307/3151897

Bauer, H. H., Sauer, N. E., \& Exler, S. (2008). Brand image and fan loyalty in professional team sport. Journal of Sport Management, 22(2), 1-25.

Berry, L. (2000). Cultivating service brand equity. Journal of the Academy of Marketing Science, 28, 128-137. http://dx.doi.org/10.1177/0092070300281012

Brady, M. K., Cronin, J. J., Fox, G. L., \& Roehm, M. L. (2008). Strategies to offset performance: The role of brand equity. Journal of Retailing, 2, 151-164. http://dx.doi.org/10.1016/j.jretai.2008.04.002

Catell, R. B. (1966). The scree test for the number of factors. Multivariate Behavioral Research. http://dx.doi.org/10.1207/s15327906mbr0102_10

Checchinato, F., Disegna, M., \& Vescovi, T. (2013). Does country of origin affect brand associations? The case of Italian brands in China. Journal of Global Scholars of Marketing Science, 23(4), 409-421. http://dx.doi.org/10.1080/21639159.2013.818281

Cobb-Walgren, C. J., Ruble, C. A., \& Donthu, N. (1995). Brand equity, brand preference, and purchase intent. Journal of Advertising, 24(3), 25-37. http://dx.doi.org/10.1080/00913367.1995.10673481

Del Rio, A., Vazquez, R., \& Iglesias, V. (2001). The effects of brand associations on consumer response. Journal of Consumer Marketing, 18, 410-425. http://dx.doi.org/10.1108/07363760110398808

Faircloth, J. B, Capella, L. M., \& Alford, B. L. (2001). The effect of brand attitude and brand image on brand equity. Journal of Marketing Theory and Practice, 9(3), 61-75. http://dx.doi.org/10.1080/10696679.2001.11501897

Griffin, A., \& Hauser, J. (1992). The voice of the customer. Marketing Science Institute, 12(4), 92-106.

Gwinner, K. P., Gremler, D. D., \& Bitner, M. J. (1998). Relational benefits in services industries: The customer's perspective. Journal of the Academy of Marketing Science, 26(2), 101-114. http://dx.doi.org/10.1177/0092070398262002

Hair, J. F., Black, W.C., Babin, B. J., Anderson, R. E., \& Tatham, R. L. (2006). Multivariate data analysis (6 ${ }^{\text {th }}$ ed.). Upper Saddle River, NJ: Prentice-Hall.

Kayaman, R., \& Aralsli, H. (2007). Customer-based brand equity: Evidence from the hotel industry. Managing Service Quality, 17(1), 92-109. http://dx.doi.org/10.1108/09604520710720692

Keller, K. L. (1993). Conceptualizing, measuring, and managing customer based brand equity. Journal of Marketing, 57(1), 1-22. http://dx.doi.org/10.2307/1252054

Keller, K. L. (1998). Strategic brand management. Upper Saddle River, NJ: Prentice-Hall.

Kim, Y., Lee, J., \& Lee, Y. (2008). Relationship between brand personality and the personality of consumers, and its application to corporate branding strategy. Journal of Global Academy of Marketing Science, 18(3), 27-57. http://dx.doi.org/10.1080/12297119.2008.9707516

Low, G. S., \& Lamb, C. W. (2000). The measurement and dimensionality of brand associations. Journal of Product and Brand Management, 9(6), 350-368. http://dx.doi.org/10.1108/10610420010356966

Maslow, A. H. (1970). Motivation and personality. New York: Harper \& Row.

Moon, B., Park, W., \& Choi, S. (2010). Relationships among brand equity components: An exploratory study of the moderating role of product type. Journal of Global Academy of Marketing Science, 20(1), 98-108. http://dx.doi.org/10.1080/12297119.2010.9707348

Nelson, D. L., McEvoy, C. L., \& Dennis, S. (2000). What is free association and what does it measure? Memory and Cognition, 28(6), 887-899. http://dx.doi.org/10.3758/BF03209337 
Nunnally, J. C. (1978). Psychometric theory. New York: McGraw-Hill.

Romaniuk, J., \& Gaillard, E. (2007). The relationship between unique brand associations, brand usage, and brand performance: Analysis across eight categories. Journal of Marketing Management, 23(3/4), 267-284. http://dx.doi.org/10.1362/026725707X196378

Sangster, A., Wolton, J., \& McKenney, S. (2001). The International Hotel Industry - Corporate strategies and global opportunities. Travel and Tourism Intelligence, London.

Srinivasan, V., Park, C. S., \& Chang, D. R. (2005). An approach to measurement, analysis, and prediction of brand equity and its sources. Stanford Research Paper Series, 1685, 1-34. http://dx.doi.org/10.1287/mnsc.1050.0405

Suhr, D. D. (2006). Exploratory or confirmatory factor analysis? Statistics and Data Analysis, 200(31), 1-17.

Supphallen, M. (2000). Understanding core brand equity: Guidelines for in-depth elicitation of brand associations. International Journal of Market Research, 42(3), 319-361.

Till, B. D., Baack, D., \& Waterman, B. (2011). Strategic brand association maps: Developing brand insights. Journal of Product \& Brand Management, 20(2), 92-100.

Uggla, H. (2004). The brand association base: A conceptual model for strategically leveraging partner brand equity. Journal of Brand Management, 12(2), 105-123. http://dx.doi.org/10.1057/palgrave.bm.2540208

Underwood, R., Bond, E., \& Baer, R. (2001). Building service brands via social identity: Lessons from the sport marketplace. Journal of Marketing Theory and Practice, 9(1), 1-13. http://dx.doi.org/10.1080/10696679.2001.11501881

Yoo, B., Donthu, N., \& Lee, S. (2000). An examination of selected marketing mix elements and brand equity. Journal of the Academy of Marketing Science, 28(2), 195-211. http://dx.doi.org/10.1177/0092070300282002 